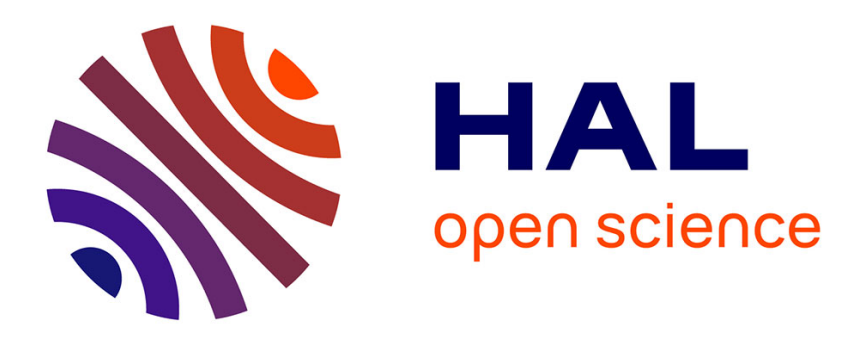

\title{
Adverbial and Relative to-Infinitives
}

Olivier Simonin

\section{To cite this version:}

Olivier Simonin. Adverbial and Relative to-Infinitives. Journal of English Linguistics, 2013, 41 (1), pp.4-32. 10.1177/0075424211428337 . hal-02433040

\section{HAL Id: hal-02433040 https://hal-univ-perp.archives-ouvertes.fr/hal-02433040}

Submitted on 22 Apr 2021

HAL is a multi-disciplinary open access archive for the deposit and dissemination of scientific research documents, whether they are published or not. The documents may come from teaching and research institutions in France or abroad, or from public or private research centers.
L'archive ouverte pluridisciplinaire HAL, est destinée au dépôt et à la diffusion de documents scientifiques de niveau recherche, publiés ou non, émanant des établissements d'enseignement et de recherche français ou étrangers, des laboratoires publics ou privés. 


\title{
$\underline{\text { Adverbial and relative } t o \text {-infinitives }}^{*}$
}

\begin{abstract}
:
The purpose of this article is to provide a new analysis of an ill-understood type of infinitival clauses, which have been previously labeled purpose clauses (e.g., Bach 1982; Jones 1991; Whelpton 1995) or elliptical infinitive clauses (Mair 1990, 1991) and are called Weak Purposive Clauses (WPCs) here. It starts with a puzzle: some infinitives can be parsed as either adverbial or relative, as is evidenced in the corpus ICE-GB - which has been used for illustrative purposes. In The spider monkey picks leaves or fruit to eat, the infinitive is potentially parsed as adverbial ('in order to eat them') or relative ('which it can then eat'). I demonstrate that those infinitives, for which the distinction is neutralized, pertain to the WPC class and need to be distinguished from typical relative infinitives and infinitival rationale clauses (traditional adverbial clauses of purpose). The semantic and syntactic properties of the class are described in full detail (meaning, control properties...), including several that have gone unnoticed (the variety of gap functions; the potential absence of gaps; "double relativization") or failed to be adequately explained (their assertoric force). It appears that for most WPCs, a continuative (i.e. relative) clause interpretation is superimposed on an adverbial one, leading to syntactic ambiguity.
\end{abstract}

KEYWORDS: purpose clause; infinitive; relative; continuative; control; ambiguity; neutralization

\section{Introduction: a puzzle of syntactic ambiguity}

When confronting corpus data, one is likely to encounter syntactic ambiguities that cannot be satisfactorily resolved, even after due consideration of the context in which they occur. This is especially true of to-infinitives in general (e.g. Quirk et al. 1985: 1269-1270), and for those that can be understood as having a relative or an adverbial (purposive) function in particular. Some infinitives occurring in corpora and natural language appear to be ambiguous between the two readings.

\section{Infinitives and syntactic ambiguity}

Consider (1):

1. A spider monkey can hang by its tail from a branch with no trouble while it picks leaves or fruit to eat. (ICE-GB: <w2b-021 030>)

The infinitive allows both an adverbial and a relative interpretation. Contextual information does not permit disambiguation here. The infinitive is irretrievably ambiguous; the distinction between the two readings is neutralized ${ }^{1}$.

Under an adverbial interpretation, the infinitive is an adjunct expressing the purpose of the picking. (1) could be rephrased:

1a. A spider monkey... picks leaves and fruit in order to eat them. 
The use of "in order + INFINITIVE" shows that the infinitive can be parsed as an adjunct. Moreover, the infinitives in (1) and (1a) are "purpose clauses", according to Cristofaro's definition (2005: 506):

A purpose construction is regarded as one encoding a particular relation between events. This relation is such that one of the linked events (the one encoded by the main clause, or the main event) is performed with the goal of obtaining the realization of another one (the one coded by the purpose clause, or the dependent event).

Here, the monkey picks leaves and fruit with a view to eating them as food.

A relative interpretation of the infinitive is no less viable. In (1), leaves and fruit can be construed as the antecedent of a relative clause, which happens to be infinitival ${ }^{2}$. Its antecedent designates things that spider monkeys eat. (1) can be rephrased:

1b. A spider monkey... picks leaves and fruit which it can then eat (or will eat).

For scholars working on relative infinitives, if an infinitive can be paraphrased with a finite relative, it is a relative clause. To quote Geisler (1995: 12):

Relative infinitive clauses form one type of non-finite postmodifier. In Mary is the person to do it the infinitive clause corresponds to the finite clause Mary is the person who should do it, where the relative marker who functions as subject of the relative clause.

The paraphrase criterion first formulated here is now consensual in the literature on relative infinitives (e.g. Delesse 2001; Akiyama 2002). Applying it leads to the conclusion that the infinitive in (1) is a relative clause.

The main problem posed by such clauses is that it does not seem justified to parse them in one way rather than another. This appears to go against the received syntactic wisdom that clauses are normally assigned one syntactic function only.

\section{Parsing inconsistencies}

This kind of ambiguity creates classificatory complications that can be observed in a parsed corpus such as ICE-GB, which was used for the present study. Although a syntactic analysis is provided for every infinitive in the corpus, the rationale behind individual choices is far from apparent with infinitives like to eat in (1). This infinitive was classified as relative, but it might have been parsed as adverbial. Since both solutions can be envisaged equally, opting for one rather than the other is arbitrary.

The charge of arbitrariness is even more difficult to dismiss with infinitives occurring in similar environments:

2. The United States is preparing to mobilise major combat units from the reserves to send to the Gulf. (<s2b-017 013>)

3. Now it's about to mobilise major combat units to send to the Gulf. (<s2b-017 017>) 
In both (2) and in (3), to send to the Gulf can be replaced with so as to send them to the Gulf, which fulfils an adverbial function, or the relative clause which it will send to the Gulf. ICEGB tagging suggests that the infinitive is an adjunct in (2), and a relative clause in (3). This classificatory problem is recurrent:

4. So basically you've got 86 pounds a week to live on. $(<\mathrm{s} 1 \mathrm{a}-078$ 136>)

5. Dr Sacks I'm not going to ask you to encapsulate your arguments in a few sentences because if that were possible the BBC would feel rather foolish I think at having offered you three hours of air time to develop them. (<s1b-028 001>)

While the infinitive in (5) is parsed as an adjunct, to live on in (4) is seen as a relative clause (You've got 86 pounds a week on which to live). Yet (5) could have equally ended with three hours of air time during/in which you could develop them. With such infinitival structures, parsing is bound to be lacking in consistency ${ }^{3}$.

\section{Outline: how to solve the puzzle}

I have presented a puzzle involving syntactic ambiguity: some infinitives can be interpreted as relative clauses or adjuncts. These are all clauses belonging to a class that I will call Weak Purposive Clauses (WPCs for short), which is the subject of this paper. To solve the initial problem, it is necessary to explore the category fully.

A general overview of WPCs is first in order. After a description of their properties with respect to gapping and constraints bearing on their occurrences, a whole battery of tests is used to differentiate them from traditional adverbial clauses of purpose or typical relative infinitives. Drawing on previous observations, the potential relative reading of WPCs is finally explained.

\section{Weak Purposive Clauses (WPCs) as a grammatical category}

After a very short historical introduction, I discuss the two potential syntactic interpretations found with most WPCs to define them, and distinguish them from other similarly "purposive" adverbial infinitives.

\section{Overview of the literature}

Jespersen may have sensed the existence of the WPC infinitival class, since he remarked that there are "infinitives having a preceding word as their notional object" (1940: 252). Here are examples he provided (emphasis mine):

6. Had he bought them to put there (Galsworthy)

7. Audrey kept this letter to show Paul (Gibbs)

8. He lent me a book to read (Gibbs) 
The presence of gaps is a staple in the relevant literature, and it is well-known that gaps do not always occur in object positions. There are prepositional complement gaps (4) and subject gaps (9), for instance.

4. So basically you've got 86 pounds a week to live on

9. They hired John to go over the reports.

Faraci (1974) was the first to provide an account of the infinitival structures under discussion. He called them purpose clauses, as opposed to rationale clauses - the adverbial clauses of purpose of traditional grammar. He was careful to distinguish purpose clauses from relative infinitives, devised syntactic tests to do so, and tentatively put forward matrix predicates that are compatible with them. Emmon Bach (1982) drew attention to the meaning of the infinitive itself as well and suggested that purpose clauses may also exhibit only a subject gap and still differ from rationale clauses - just like the infinitive in (9). Christian Mair (1990, 1991) coined the term elliptical infinitive clauses to refer to "a number of infinitival clauses that are marked by characteristic elliptical gaps" (1990: 210; $c f$. Huddleston and Pullum's [2002, 729] "ungoverned infinitivals with a missing non-subject"). His corpus study presents a valuable list of predicates with which such infinitives occur. Others like Kirkpatrick (1982), Jones (1985, 1991), Green $(1991,1992)$ and Whelpton (1995) took up and refined the concepts, tests and observations inherited from their predecessors.

The picture emerging from this hasty sketch shows that authors use purpose clause (or any term of their own making) to refer to a category that is often only superficially congruent with that meant by others. My own term weak purposive clause is no exception.

\section{Syntactic ambiguity and WPCs}

Let's return to the syntactic ambiguity of the infinitives already reviewed. I start with simple assumptions on their potential interpretations:

I. Adverbial interpretation: has a resultative component to which the purposive meaning is apt to be reduced; paraphrases with clauses introduced with so that can be felicitous.

II. Relative interpretation: the infinitive is a non-restrictive relative clause; it does not contribute to restricting the reference of its antecedent, which is definable without it.

The infinitives in (4) and (5) lend themselves to a resultative reading ( $s$ indicates a paraphrase with so that):

4s. So basically you've got 86 pounds a week so that you can live on those.

$5 \mathrm{~s}$....the BBC would feel rather foolish I think at having offered you three hours of air time so that you could develop them [your arguments].

The paraphrases are stylistically awkward, but they show that the adverbial meaning of the infinitives is partly resultative: the state of affairs coded in the matrix clause ('have 86 pounds a week'; 'having offered you three hours') amounts to a precondition for the event coded by the infinitive to become possible ('to live on that amount'; 'to develop your ideas'). In (4), the matrix clause situation has not been brought about with a view to obtaining the realization of the infinitive event: you've got 86 pounds a week signals a state that cannot straightforwardly be imputed to anyone's volition. In (5), the hypothetical offer would have been made to give 
Dr Sacks the opportunity to present his arguments in detail, which is understood as its tacit rationale.

Other infinitives like (1) or (9), more easily described as purposive, can be shown to be resultative. A spider monkey picking leaves and fruit is then able to eat them; hiring John makes it possible for him to be employed. The eating itself or the paperwork occurs as a result of the goal set by the subject referent ('the monkey'; 'John's employers').

Non-restrictiveness is required in the relative interpretation ${ }^{4}$. For the sake of argument, let's assume that in (1), leaves and fruit to eat had been replaced with something to eat:

10. A spider monkey can hang by its tail from a branch with no trouble while it picks something to eat.

Under a relative interpretation, the infinitive is restrictive: it pinpoints what is picked up. The infinitive is not adverbial because it complements a noun. Though to eat might convey a sense of purpose, it is not an adjunct. But the same infinitive in (1) can be parsed as an adjunct or a non-restrictive relative.

Now the ground has been fully prepared to define WPCs. By Weak Purposive Clauses I understand adjunct infinitival clauses whose meaning is partly resultative: the situation coded in the matrix clause renders the realization of the one coded by the infinitive possible. This resultative meaning is often tinged with a sense of purpose that is weak, when it does not disappear altogether. WPCs almost systematically give rise to grammatical ambiguity, since they can also be parsed as non-restrictive relative infinitives - except in a few well-defined cases (see the penultimate subsection). While the acronym WPCs indicates a focus on the adverbial reading, WPC infinitive is sometimes used for an infinitive that can be parsed as a WPC, regardless of the possibility of ambiguity.

\section{Purpose clauses, Purposive clauses, rationale clauses and WPCs}

Purpose clause is a term with several acceptations. Faraci (1974) used it to describe purposive clauses with gaps, which he opposed to rationale clauses - traditional adverbial clauses expressing purpose. Both terms were taken up after him by linguists who shared an interest in those structures (Bach, Jones, Green, Whelpton...). On the other hand, purpose clause is also used as a generic term, covering all adjunct clauses with a purposive purport (e.g., Huddleston and Pullum 2002, van der Wurff 2002 and Cristofaro 2005). To avoid any equivocation, I employ purposive clauses generically (for adverbial clauses). The category straddles WPCs and rationale clauses, so purposive is meant in the loose sense 'connected with purpose'.

\section{FIGURE 1}

\section{Purposive Clauses}

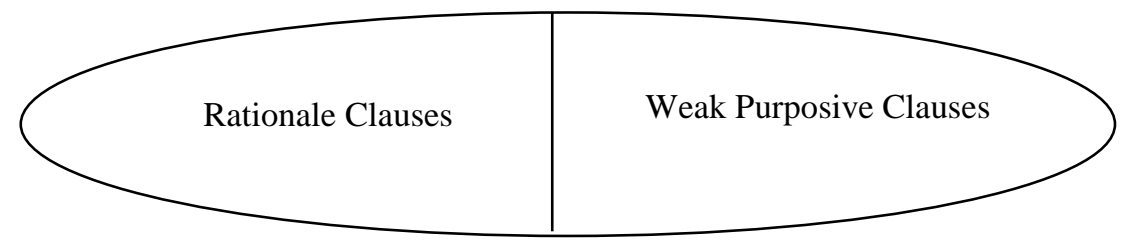


I do not discuss Whelpton's $(1995,2001)$ telic infinitives, which are related and state a specific outcome (John left early in the morning, to return late at night), nor do I consider predicative uses of infinitives (Giraffes have long legs and necks to eat leaves from trees), which are often regarded as making up a type of their own (genetic purpose expressions for Kitagawa 1974, 1976; purpose predicates for Whelpton 1995).

\section{Gaps and WPCs}

The number of gaps in WPCs varies from zero to two. The syntactic functions they fulfill are wider-ranging than previously thought.

\section{Number of gaps: one, two or none}

When there are two gaps in the infinitive, or more generally when there is a non-subject gap, WPCs cannot be confused with rationale clauses. The infinitives of (1) and (2) contain two gaps and should be parsed as WPCs:

1. A spider monkey can hang by its tail... while it picks leaves or fruit _ $\mathrm{S}_{-}$to eat _ $\mathrm{O} \_$.

$\rightarrow$ The spider monkey (S) will eat leaves or fruit $(\mathrm{O})$.

2. The United States is preparing to mobilise major combat units from the reserves _ $\mathrm{S}$ _ to send _ $\mathrm{O}$ _ to the Gulf.

$\rightarrow$ The United States (S) will send combats units $(\mathrm{O})$ to the Gulf.

On the other hand, one can also find WPCs with one gap only:

9. They hired John __ __ to go over the reports.

11. Colonel Charteris ... was again supposed to have used prostitutes to procure innocent young virgins for him to seduce __

In (9), there is only a subject gap in the WPC. (11) contains a WPC with two conjoined VPs. It has two non-subject gaps and its subject position is filled, the infinitive having the form for $X$ to. With WPCs that have a non-subject gap and whose subject is not coreferential with the head noun preceding the infinitive, for $X$ to can be used for the subject position to be filled.

The introduction of an explicit subject with for $X$ to infinitives poses an intriguing problem for passive WPCs with one subject gap only:

12. The documents were passed on to the records department ___ _ _ to be classified.

Of course, the active counterpart of the passive infinitive would be a straightforward WPC like for them to classify (with an object gap). Now, the subject position of passive infinitives can be filled, as in (13):

13. The documents were passed on to the records department for them to be classified. 
Unless one wishes to assume that the clause might contain a gap for the agent (whoever was supposed to classify the documents), it appears that infinitives without any gaps can be WPCs - a remarkable fact.

\section{Gaps and syntactic functions}

For a significant number of WPC infinitives, non-subject gaps can be postulated. Consider (5) again:

5. ... if that were possible the BBC would feel rather foolish I think at having offered you three hours of air time to develop them.

If the infinitives are rewritten as finite relative clauses, a pied-piped preposition can appear: (three hours of air time) in which you could develop them. This suggests that the head noun preceding the infinitive can be seen as filling a gap within the infinitive (a time-adverbial gap here - as in the finite relative clause the day (when/on which) he came ). The presence of this gap is not obvious because the infinitive clause looks complete without it: no argument or verbal complement appears to be lacking. Similarly for (14):

14. Other useful options include multitone ringers, _ $\mathrm{S}$ _ to positively identify a special line. $(<w 2 b-032$ 031>)

Although multitone ringers can be construed as coreferential with the subject gap, it can also be understood as an instrument thanks to which it is possible to positively identify a special line. The infinitive could be rewritten as a finite clause: Customers can positively identify a special line with multitone ringers. Under this reading, the implicit subject of the infinitive can be introduced with for $X$ to:

15. Other useful options include multitone ringers, for customers to positively identify a special line (with)

The optional stranded preposition strongly argues for the presence of a gap in the infinitive.

The head noun preceding a WPC can be coreferential to a gap occupying a limited set of syntactic functions within the infinitive, listed here:

\section{i/ Subject:}

9. They hired John __ __ to go over the reports.

12. The documents were passed on to the records department ___ __ to be classified.

ii/ Object (direct or prepositional):

3. Now it's about to mobilise major combat units to send__DO_ to the Gulf.

16. ... that old gusto of that century is still there to draw upon__ $\mathrm{PO}$ _ and to stir__ $\mathrm{DO}$ _ into the slipstreams of the current fads of the new technologies... $(<\mathrm{s} 2 \mathrm{a}-040018>)$

iii/ Instrument (with or without a stranded preposition):

14. Other useful options include multitone ringers, to positively identify a special line __ I_. 
17. Did you have pins to pick them out with ____? (<s1a-009 299>)

iv/ Other adverbial function (time, location...): ${ }^{5}$

5. If that were possible the BBC would feel rather foolish I think at having offered you three hours of air time to develop them _ $\mathrm{T}$. .

18. By then, the Gauls had their own Roman baths to relax and enjoy active social life __ $\mathrm{L}_{-}$

v/ Complement to a preposition following a predicative adjective:

19. He had his son's achievements to be proud of __ _ _ .

The fact that adverbial gaps tend to appear without a stranded preposition makes it likely for WPCs to be confused with rationale clauses. The same problem arises for WPCs with one subject gap only.

\section{Constraints on WPCs: distribution, control and semantics}

Some general constraints are explored for WPC occurrences, bearing on the matrix clause, control, and the meaning of WPCs.

\section{Constraints on the matrix clause}

WPCs occur within a restricted number of matrix clause constructions. Bach was the first to offer a typology of compatible matrix clause predicates $(1982,38)$. Drawing on corpus data, Mair (1990: 212) finds that there are two main categories of matrix verbs that naturally cooccur with WPCs: "give, or more or less close synonyms" and verbs that "revolve around the ideas of taking, acquiring, choosing or using for a specific purpose":

20. [...] and also thank her for the much appreciated cherry cake she gave me to bring up here.

21. [...] the thug is invariably a coward - he generally seems to select an elderly defenceless woman to attack and rob.

He then lists other possible matrix verbs found with WPCs. One of Bach's insights is that the matrix clause entails - as a resultant state - the availability of the entity represented by a gap in the infinitive. Mair's examples corroborates Bach's claim. Constructions not allowing for the availability of the entity denoted by the gapped element are not acceptable. Re-writing (21) into (22), in which no such availability is entailed, fails to yield a felicitous sentence ${ }^{6}$ :

22. *The thug generally seems to shun elderly women to attack and rob.

Even in WPCs with no gap (15), the entity denoted by the explicit subject (The documents were passed on to the Records department for them to be classified) must be made available (if the documents are passed on, they are ready to be classified). In her 1991 and 1992 papers, Green refined the notion of availability. She drew attention to matrix constructions denoting states, with verbs like be, which Bach simply mentioned. 
With matrix predicates like be there, availability is inferred. It might have been brought about on purpose, which is probable in (23), but this does not need to be the case. No intentionality is involved in (24) or (25):

24. It's all there for people to pick up. $(<\mathrm{s} 2 \mathrm{a}-027117>)$

25. They also find little known stories and folk tales of Christian saints and though history and legend are tightly woven together the truth is always there to see $(<\mathrm{s} 2 \mathrm{~b}-027$ 162>)

Whelpton (2006: 211) further notes that the resultant state specified by the matrix predicate requires the available element to possess "a property that will allow it to serve the function described." While John polished the silver platter to use as a mirror is acceptable, replacing polished with rubbed would lead to an ungrammatical result. The matrix predicate must entail that the entity denoted by the gapped element is both available and in an appropriate state.

\section{Control}

When there is a non-subject gap in the WPC, it corresponds to the element whose availability is entailed (the arrow indicates that the gap is coreferential with the element at its base):

1. It picks leaves or fruit to eat

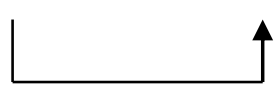

When there is only a subject gap, the element available or made available controls it:

9. They hired him to go over the reports.

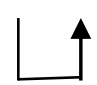

I will follow standard usage in using the term control with reference to subject gaps only, as in (9). Here is a simplified minimalist representation of (9):

[тр They [т Af] vр [They [v hire] DP [him] [тP [т to] [PRO vP [v go] рP [over the reports]]]]]

I do not wish to enter any theory-internal debate as to how to treat non-subject gaps formally. The arrow representations chosen here are informal, but the observations underlying them can be adapted to fit various syntactic theories. Let us now concentrate on the question of control in WPCs with a subject and a non-subject gap.

In (1), the implicit subject of the infinitive is coreferential with the matrix subject:

1. It picks leaves or fruit to eat.

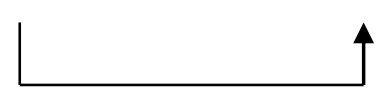

One could then perhaps postulate the same control mechanism for rationale clauses and WPCs: the subject/agent of the matrix clause is the controller (for refinements, see Culicover 
and Jackendoff 2005: 426-427). This works for (26) and (27), whose infinitives are rationale clauses (<s1b-044 139> and <w2d-018 055>, respectively):

26. We've got to use our rationality and our emotions

. It may be necessary to scrape paint... to determine the lining thickness.

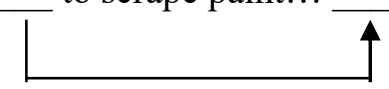
to make better decisions...

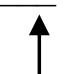

In (26), with arbitrary or free control (Landau 2000; Jackendoff and Culicover 2003), the unexpressed controller of to scrape paint... is identical to that of the infinitive clause to determine the lining thickness.

However, many WPCs simply fail to follow the control mechanism that holds for rationale clauses:

5. If that were possible the BBC would feel rather foolish I think at having offered you three hours of air time to develop them.

\section{$\uparrow$}

20. [...] and also thank her for the much appreciated cherry cake she gave me to bring up here.

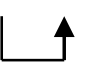

The best generalization is that the controller of the WPC subject corresponds to whomever the availability predicated in the matrix clause (or entailed) befalls. It is the addressee (' $y o u$ ') in (5) and the speaker (' $I$ ') in (28). This also holds for (1) and similar occurrences ${ }^{8}$ : the matrix subject (it) refers to whoever enjoys the relevant availability ('a spider monkey').

Rules establishing to which referents WPC gaps correspond are already stated in Bach (1982) and further developed by Jones (1985: 1991) and Green (1991, 1992), though none of them would not regard the infinitive in (5) as having a non-subject gap, and therefore as being a WPC. The rules that have been brought to light account for this infinitive as for any WPC. They are idiosyncratic to WPCs and do not apply to rationale clauses.

\section{Meaning of the infinitive clause}

There is a semantic constraint on the signification of WPCs: they cannot convey a full-fledged purpose meaning, as rationale clauses. The sense of purpose is weak, if not altogether absent, when its resultative component comes to the fore.

28. I bought Bambi to give to Mary to pass on to John to take along on the camping trip to read to the children.

Commenting on this intricate series of WPCs (emphasis mine), Bach writes (1982: 54): 
To understand this sentence... we need to track the succession of "availability states"... I buy Bambi; I have Bambi; I'm going to give it to Mary; then Mary will have it; she's supposed to pass it on to John; then he'll have it and will be able to take it along on the camping trip and it will be on hand (for John or anyone else on the trip) to read to the children.

Phrases like will be able to and will be on hand are especially significant. Instead of simply saying that WPCs are weak purposive infinitives, one can pinpoint their meaning by means of a paraphrase:

"so that it was/is/will... be possible for $\mathbf{X}$ to be done."

For $X$ to be done stands for the situation coded by the infinitive. Any trace of intentionality is absent from the paraphrase offered.

Intentionality (/purpose) has been commented on at length in the literature. Consider (29) (emphasis mine):

29. Carol bought a rack to hang coats on.

Regarding it, Faraci (1974: 10-11) wrote:

On the purpose clause [WPC] reading of [29], the infinitival adjunct is used to assert something about the object $a$ rack. What is asserted is that the rack serves the purpose of being something to hang coats on.

Generalizing from his remarks, I propose that:

The element whose availability is predicated in the matrix clause (/entailed) is earmarked for the use stated by the WPCs.

In (29), Carol earmarked the rack for the purpose of hanging coats. Intentionality can thus be attributed to her for the action of purchasing a rack.

Even with examples like (25) - The truth is always there to see - it is possible to argue that the speaker (or someone else) envisages the available element (truth) in the sole light of the potential use stated, for the purpose conveyed by the infinitive (to see it; to observe it). Although no intentionality or purpose is involved, earmarking is still a relevant concept. It is capable of accounting for WPCs that retain a strong purposive flavor and those which do not.

Let's illustrate the resultative meaning of WPCs and earmarking. In (1), it picks leaves or fruit to eat:

A. The monkey picks leaves and fruit so that it can eat them

B. Such leaves and fruit are earmarked (by the monkey) for (the purpose of) eating

(A) develops the adverbial interpretation of the infinitival clause. (B) goes some way towards explaining that it can also be parsed as relative: leaves or fruit is postmodified by to eat, which states that these have been earmarked for consumption. The phrase leaves or fruit can be regarded as an antecedent, assuming Givòn's semantic definition of relative clauses (1990: 646): 
A relative clause codes a proposition one of whose participants is coreferential with the head noun that is modified by the clause.

In sum, syntactic ambiguity for infinitives that can be parsed as WPCs is secured by the fact that they are naturally amenable to a relative interpretation. This interpretation is triggered by the weak purposive meaning of the infinitive, derived from an initial WPC understanding:

WPCs imply that something is available, in a fit state, so that it is possible for $\mathrm{X}$ to be done.

$\rightarrow$ A property is attributed to that something: it is earmarked for a given use.

$\rightarrow$ It is considered/earmarked for a use its availability makes possible.

$\rightarrow$ A relative interpretation is apt to be derived from this "weak" purposive meaning.

\section{Rationale clauses and WPCs}

Because WPCs have a purposive meaning and their gaps are not always conspicuous, they can easily be confused with rationale clauses. A syntactic test to distinguish the two classes is first put forward and their respective meanings is then discussed.

\section{Distinguishing WPCs from rationale clauses}

As previously mentioned, (26) and (27) contain rationale clauses:

26. We've got to use our rationality and our emotions to make better decisions for our patients.

27. It may be necessary to scrape paint from the edge of the shoe to determine the lining thickness.

(26) and (27) are compatible with in order insertion (indicated with $i$ below), a popular test to tease out rationale clauses:

26i. We've got to use our rationality and our emotions in order to make better decisions for our patients.

27i.It may be necessary to scrape paint from the edge of the shoe in order to determine the lining thickness.

The test does not work for WPCs. For them two cases need to be distinguished, depending on whether the infinitive contains a conspicuous non-subject gap or not.

When there is an object gap or a gap after a preposition, the infinitive is obviously a WPC, and in order insertion is ungrammatical.

3. Now it's about to mobilise major combat units (*in order) to send to the Gulf.

17. Did you have pins $(*$ in order $)$ to pick them out with ___?

Otherwise, the infinitive superficially looks like a rationale clause, but it still does not license in order insertion - witness the infinitives in (9) and (14):

9i. *! They hired him in order to go over the reports. 
14i.?! Other useful options include multitone ringers, in order to positively identify a special line.

The syntactic and semantic propinquity of WPCs and rationale clauses may go some way towards explaining that sentences like (9i) and (14i) are not unremittingly ungrammatical. The insertion test works for (1), however, whose infinitive is ambiguous between an adjunct and a relative reading:

1i. A spider monkey... picks leaves and fruit in order to eat.

When compared to the original utterance, a shift in meaning has occurred. While (1) implies that the monkey picks leaves and fruit with a view to eating them, (1i) states that the monkey does so in order just to eat, i.e. to have something to eat. Under this reading, eat is used intransitively, without an object, while it is used transitively in (1). A better way to rewrite (1) is to substitute in order to eat them to the infinitive or, even better, to use so that instead of in order:

1s. A spider monkey... picks leaves and fruit so that it can eat them subsequently.

The argument of eat is made explicit, and the original meaning is preserved. It follows that the infinitive in (1) is not a rationale clause, despite its compatibility with in order insertion. It is another type of purposive adjunct: a WPC.

A further complication arises with infinitives that might equally receive a WPC or a rationale clause interpretation. For instance the infinitive in (26) can potentially be parsed as a WPC, since it can be replaced by a finite relative clause: We've got to use our rationality and our emotions, through which we will then be able to make better judgments for our patients. Another example is (13):

13. The documents were passed on to the records department for them to be classified.

Yet although in order insertion yields an acceptable sentence here (in order for them to be classified: with perhaps too strong an emphasis on volition), substitution with a relative clause does not (*The documents were passed on to the records department, which were to be classified). This is because the antecedent is at the beginning of the matrix clause (see the penultimate subsection). For infinitives that do not have a tell-tale syntactic structure to differentiate WPCs from rationale clauses - as in (13) and (26) - it is necessary to resort to semantic considerations to remove the ambiguity.

\section{Non-synonymy}

The semantic distinction between rationale clauses and WPCs is best illustrated by revisiting observations made in Quirk 1977, regarding the contrast between two infinitives:

30. I have (Here is) a book for you to read (*it).

(WPC)

31. I specifically brought the book (in order) for John to read it.

(RAC)

Quirk was careful not to classify the infinitive in (30) among "purpose clauses", since volition is not as strong as in (31), where the matrix subject is "volitionally active" (Quirk 1977: 101). The difference between the two infinitives derives from their distinct functions: while for you 
to read is a WPC, the infinitive in (31) is a rationale clause (RAC). Quirk mentions on the same page that "a certain amount of contextualization seems necessary to make the... object obligatory" in the infinitive. In (30) the matrix clause is hardly compatible with a rationale clause, as have does not suggest a strongly agentive possessor. On the other hand, specifically brought the book suggests a fully agentive actor, and calls for a rationale clause.

Sometimes, the matrix construction is compatible with both types of infinitives:

32. I did not give you this bat to beat your friends with it.

(RAC)

33. I did not give you this bat to beat your friends with

Commenting on similar oppositions, Jones remarks that utterances with rationale clauses have agentive connotations, which those with WPCs lack (Jones 1991: 216-223).

When there is potential ambiguity between rationale clauses and WPCs, each syntactic interpretation correspond to a distinct meaning:

34. I did not give you this bat to beat your friends

To beat your friends can be parsed as a rationale clause (in order for you to beat your friends), with fully volitional connotations. Yet it can also be construed as a WPC (so that you could beat your friends), in which case the bat is understood as the instrument or the means for the action to occur, although no non-subject gap conspicuously features in the infinitive. The same type of ambiguity is found in (26), reproduced here:

26. We've got to use our rationality and our emotions to make better decisions for our patients.

Now in (26), the notion of purpose is strongly implicated for the infinitive clause, which argues for a rationale clause reading. Similarly, the potential ambiguity noted for (13) may disappear when semantics is taken into account.

13. The documents were passed on to the records department for them to be classified.

The documents have been passed on to the records department with an intention to have them classified, which is either fully or not fully purposive. A fully purposive intention corresponds to a rationale clause interpretation, and a weaker one to a WPC interpretation. In the first case, what is coded is that whoever brought about the transfer of the documents did so with a clear view to obtaining their filing, which is pursued as a goal. In the second case, purposive meaning is still expressed, but not so directly - and more weakly as a result. The purposive meaning of WPCs is derived contextually and is therefore subject to variation. In short, even WPCs that appear to retain a good dose of purpose have a purposive meaning that is weaker than that of rationale clauses, not being fully coded.

\section{WPC infinitives and relative infinitives}

After having established that WPC infinitives cannot be interpreted as restrictive relatives, as opposed to typical relative infinitives, I introduce syntactic tests and highlight positional constraints to distinguish the two groups. 


\section{Distinguishing WPC infinitives from relative infinitives}

When WPCs have a non-subject gap, they are likely to be misanalyzed as typical, restrictive relative infinitives. Most WPC infinitives provided as illustrations so far can be paraphrased with finite relative clauses. Here are some examples ( $r$ indicates a relative paraphrase):

2r. The United States is preparing to mobilise major combat units from the reserves which it will send to the Gulf.

5r. If that were possible the BBC would feel rather foolish I think at having offered you three hours of air time during which you would develop them.

11r. Colonel Charteris ... was again supposed to have used prostitutes to procure innocent young virgins whom he could seduce and then turn into prostitutes.

14r. Other useful options include multitone ringers, which can/with which you can positively identify a special line.

Accordingly, those infinitives can be parsed as relative clauses. It has long been remarked that relative infinitives often express purpose, albeit with various degrees of salience (Onions 1971 [1904]: 115; Poutsma 1929 [1914]: 777). In He's the man to do the job, the (adjectival) relative infinitive to do the job conveys a sense of purpose, though the infinitive is not an adjunct.

WPC infinitives with non-subject gaps differ from typical relative infinitives, which I will refer to as infinitival relative clauses by convention (IRCs for short). Contrary to WPC infinitives, these infinitives are never interpreted as adjuncts. They are straightforward noun postmodifiers.

35. No data to support this have been published. (<w2a-033 039>)

36. He'd already given Xepe the money to get the strawbs and Pimm's. (<s1a-005 233>)

Both (35) and (36) contain IRCs. In (35), to support this appears before the matrix verb, just after a noun (data) heading the subject NP. As a result, its function cannot be adverbial. In (36), the infinitive restricts the denotation of money: it is just the amount of money necessary to purchase the products intended. Without the definite article (He's already given Xepe money to get the strawbs and Pimm's), the amount of money is left unspecified, and the infinitive does not contribute to restricting the reference of the money involved in so direct a manner - i.e. the amount could be higher (or even lower) than sufficient. The infinitive would then have been amenable to a WPC and a relative clause reading. By contrast, if an infinitive is a restrictive relative, adjunct readings are ruled out.

In sum, WPC infinitives should not be confused with IRCs - relative infinitives that cannot be parsed as adjuncts as well. WPC infinitives are adjuncts, and if they are ambiguous with a relative reading, their relative interpretation has to be non-restrictive.

\section{Syntactic tests: WPC infinitives versus (restrictive) IRCs}


A whole battery of tests has been devised to show that WPC infinitives are not constituents that directly depend on a preceding noun head: (a) it substitution, (b) pseudo-clefting, (c) passivization, and (d) the contrastive test.

Let's start with it substitution. When the element available is not already represented by a pro-NP like it (e.g. (24): it's all there for people to pick up), a possible substitution by it (or any other personal pro-NP: none...) distinguishes WPC infinitives from IRCs:

25. ...the truth is always there to see.

$\rightarrow$ It is always there to see.

28. I bought Bambi to give to Mary to pass on to John to take along on the camping trip to read to the children.

$\rightarrow$ I bought it to give to Mary...

29. Carol bought a rack to hang coats on.

$\rightarrow$ Carol bought it to hang coats on.

The test does not work with IRCs:

35. No data to support this have been published.

(IRC)

$\rightarrow *$ None to support this have been published.

36. He'd already given Xepe the money to get the strawbs and Pimm's.

$\rightarrow *$ He's already given Xepe it to get the strawbs and Pimm's.

Regarding (36), He's already given it to Xepe to get the strawbs and Pimm's is acceptable after reordering the objects. Nevertheless, the meaning is different: the sum of money is fixed in advance, while (36) implies that the amount of money is defined in the given situation - i.e. the right amount for the planned purchase. The test fails for (35) too.

The personal pro-NP does not have to be it. For instance, it can be plural:

1. It picks leaves or fruit to eat.

$\rightarrow$ It picks them to eat.

(WPC)

2. The United States is preparing to mobilise major combat units from the reserves to send to the Gulf.

$\rightarrow$ The United States is preparing to mobilise them from the reserves to send to the Gulf.

With presentational structures like I have/Here is (+ indefinite NP), it is more appropriate to use a demonstrative pro-NP or a more complex NP, as in (30):

30. I have (Here is) a book for you to read (*it).

(WPC)

$\rightarrow$ I have (Here is) this/ one of those (books) for you to read.

All in all, the test clearly shows that WPCs are not NP constituents depending on a noun head. Faraci (1974), who suggested it substitution as a criterion to distinguish WPCs from IRCs, also proposed (b) a pseudo-clefting test and (c) a passivization test for the same purpose:

1. It picks leaves or fruit to eat.

$\rightarrow$ What it picks to eat is leaves or fruit.

(B: PSEUDO-CLEFTING) 
36. He'd already given Xepe the money to get the strawbs and Pimm's.

$\rightarrow$ What he'd already given Xepe is the money to get the strawbs and Pimm's. (B)

$\rightarrow$ The money to get the strawbs and Pimm's had already been given to Xepe. (C)

The IRCs under consideration syntactically depend on their head nouns, from which they cannot be split. If an infinitive can become separated from a preceding head noun and stand in an adverbial position through pseudo-clefting or passivization, then it is a WPC infinitive. The main problem with the two tests is that their application is not always straightforward.

35. No data to support this have been published.

$\rightarrow$ What has not been published is data to support this.

\section{(B: PSEUDO-CLEFTING)}

For (35), pseudo-clefting is possible but involves some minor changes: no has become not and does not immediately precede the $\mathrm{N}$ data. As the sentence is already passive, there is no need to run the passivization test: the infinitive to support this being attached to the head noun data, it is an IRC. Yet passivization can be awkward or even ungrammatical. (30) is a case in point: I have (Here is) a book for you to read does not passivize.

There is another test, perhaps more worthy of attention: the contrastive test (Whelpton 1995: 103-104). It makes it possible to disambiguate infinitives that can be parsed as WPCs or (restrictive) IRCs. Consider (37):

37. Sven took the video to show to his mother.

$\rightarrow \quad$ i. What Sven took to show to his mother was the video. (WPC)

ii. What Sven took was the video to show to his mother. (IRC)

The pseudo-clefting test indicates that the infinitive can be understood as a WPC (Sven took it to show to his mother) or an IRC (Sven took it - the video to show to his mother). To quote Whelpton (1995: 104), if the infinitive is an IRC, it is:

... in fact a restrictive relative, and therefore implies that there is some set of videos and that this is the one which Sven intends to show to his mother. This infinitive therefore occurs naturally with the N' anaphora one in a contrastive meaning.

Hence the possibility of contrasting the video in question with another:

38. Sven took the video to show to his mother but not the one to show to his father.

The contrastive test (d) relies on the fact that - contrary to IRCs - WPC infinitives do not restrict the reference of a head noun ${ }^{9}$. All these tests corroborate the analysis according to which WPCs are not NP constituents syntactically dependent on a preceding noun head, contrary to restrictive IRCs with which they can be confused.

\section{Some positional constraints for WPCs and restrictive IRCs}

Two positional constraints are worthy of note. Firstly, "an infinitive modifier that follows subject position must be an IRC." (Jones 1991: 48) The infinitives in (39), (40), and (35) are IRCs: 
39. The man to fix the sink is here.

40. A pan to fry eggs in was on the burner.

35. No data to support this have been published.

Although WPCs cannot appear just after an initial subject (referring to the available element), they are liable to float to some extent. Some occur initially, or as interpolated clauses ${ }^{10}$ :

41. To fry eggs in, I always use a smaller pan.

(WPC)

42. He bought, to make omelets with, every bloody skillet in the store.

There is little surprise that WPCs behave like adjuncts and IRCs like restrictive relatives (which seldom appear separated from their head nouns).

Secondly, WPCs and (restrictive) IRCs behave differently with head nouns modified by finite restrictive relatives (Kirkpatrick 1982: 101). WPCs can occur after a finite relative clause, but not before ${ }^{11}$ :

43. I brought a pan that's stainless to fry eggs in.

(WPC)

Conversely, restrictive IRCs necessarily occur before the finite relative:

44. A pan to fry eggs in that's stainless is in the sink.

(IRC)

45. * A pan that's stainless to fry eggs in is in the sink.

Since the WPC does not directly depend on the noun heading a pan that's stainless (43), it cannot appear between pan and that's stainless. On the other hand the IRC to fry eggs in can, as an argument of the NP a pan to fry eggs in that's stainless (44). As a zero relative (relative with no apparent relative pronoun or complementizer), it has to occur first for the construction to be grammatical. If a that-relative is inserted before it, the sentence is ungrammatical (45). This particular constraint on grammaticality can be derived from Doherty's generalization that zero relatives "must be adjacent to the noun phrase they modify." (2000: 60)

\section{What kind of relatives are WPCs?}

From the syntactic tests previously devised to distinguish WPC infinitives from restrictive IRCs, I have deliberately excluded another test, which highlights the information structure of WPCs, and gives a clue as to what kind of relatives they may be. WPC infinitives are ambiguous and, in addition to purposive adjuncts, they can be interpreted as continuative clauses. They allow what could be called double relativization: matrix clauses with WPC infinitives can themselves be embedded as relative clauses.

\section{Answers to yes/no questions}

Kirkpatrick (1982: 102-103) devised a test which requires turning the original utterance into a yes/no question, and then giving a negative answer to that question to negate the content of the infinitive. Let us see how (40) and (43) react to the experiment: 
40. A pan to fry eggs in was on the burner. $\rightarrow$ A: Is there a pan to fry eggs in?

43. I brought a pan that's stainless to fry eggs in. $\rightarrow$ A: Did you bring that to fry eggs in?
(IRC)

B: * No, it's only for stir-frying vegetables.

(WPC)

B: No, it's only for stir-frying vegetables.

If the semantic content of the infinitive can be modified, the infinitive is a WPC (43), and an IRC (40) if not. Kirkpatrick provides the following explanation (1982: 102):

A relative clause does not contribute to the general assertoric force of a proposition. Rather, it presupposes its own truth.

The truth and content of a relative clause being presupposed, they cannot be negated, contrary to WPCs and other adverbial clauses.

Nevertheless, this is not true of all relative clauses. Some can be negated: continuative clauses, which Jespersen (1927: 105) described as relative clauses in final position, whose relative pronoun could be replaced with the conjunction and plus a personal pronoun. Both (46) and (47) contain finite continuative clauses, and react like WPCs to negation.

46. Mike gave the ball to Paul, who passed it on to John (= and he passed it on to John).

- ?! No, Mike didn't/ No, in fact, Mike did not give the ball to Paul.

- No, Paul didn't (pass it on to John).

47. He had dinner with Sarah, who was quite charming (= and she was quite charming).

- ?! No, he didn't/ No, in fact, he did not have dinner with her (but lunch).

- No, she wasn't. She was in a foul mood.

It is as if there were two coordinated clauses (with and). The continuative clause, coming last, is easier to negate than the initial one. Adding in fact is welcome for that purpose. Regarding continuative clauses, Huddleston and Pullum observe (2002: 1064):

Whereas elsewhere the information conveyed in a supplementary [i.e. non-restrictive] relative is somewhat backgrounded relative to that conveyed in the clause containing the anchor, the continuative relative has equality of informational status, presenting a further event in a narrative chain.

Continuative clauses are often simply regarded as final non-restrictive relative clauses which present new information about the next event in a sequence (Hannay and Mackenzie 1996: 114). While this is an accurate description of the relative clause in (46), it does not apply to (47): the two events it denotes are not consecutive. Rydén (1966: xlviii) proposes to call the former progressive (instead of which I prefer narrative to avoid confusion). One can then postulate the existence of continuative clauses that do not present a new link in a narrative sequence. At any rate, to distinguish continuative clauses from other relative clauses is useful to highlight the specific informational status of this subclass of non-restrictive relatives.

Since (most) WPC infinitives can be paraphrased with finite relative clauses, they could be regarded as continuative clauses, and not merely as adjuncts. Clauses ending with WPCs and finite continuatives react to negation in essentially the same way: negating the content of a WPC or finite continuative is straightforward and easier than doing the same for the matrix event. Correction markers are then especially helpful. In (47), instead of negating the content of the WPC, the speaker could have realized that he spoke too quickly, and 
declared: Well, in fact, I didn't bring any pan that's stainless. The suggestion that WPC infinitives might be continuatives is pursued in the next subsection.

\section{WPCs as continuative clauses}

A WPC infinitive attributes a property to a referent, and this element is earmarked for a given use. Keeping in mind that the relative reading of a WPC infinitive amounts to a continuative reading, I suggest that the meaning of such infinitives and their matrix clauses should be decomposed following the model given for (1):

1. ...it picks leaves or fruit to eat.

$\rightarrow$ 'It picks leaves or fruit' + 'the leaves or fruit are (earmarked) for (the purpose of) eating'

WPC infinitives can then be parsed as adjuncts or continuative clauses, which accounts for the systematic ambiguity between the two interpretations.

Yet not all WPC infinitives can receive a relative interpretation. The possibility itself is fully context-dependent. For a continuative clause to be grammatical, its antecedent must be strictly adjacent (A) and come before it (B), without being a pro-NP like it or him (C):

48. * Mike gave the ball, who passed it on to John, to Paul.

49. * Mike gave the ball to Paul, which then went into the air.

50. ?* Mike gave the ball to him, who passed it on to John.

The same holds for WPC infinitives. In these syntactic contexts, a paraphrase with a finite relative clause is ungrammatical, and the WPC cannot be regarded as relative:

(A)

41. To fry eggs in, I always use a smaller pan.

$\rightarrow *$ Which can be used to fry eggs, I always use a smaller pan.

(B)

25. The truth is always there to see.

$\rightarrow *$ The truth is always there, which you can see.

13. The documents were passed on to the records department to be classified.

$\rightarrow *$ The documents were passed on to the records department, which could then be classified.

(C)

9. They hired him to go over the reports.

$\rightarrow *$ They hired him, who could then go over the reports.

These infinitives are WPCs that cannot be equally construed as relative clauses.

\section{Double relativization}

The other curious fact about continuative WPCs is that their own matrix clauses can become embedded, as if relativization occurred twice. 
51. I enjoyed the time that I was given to study... (<s1a-001 032>)

If you consider the sentence I was given time to study, the infinitive can be parsed as relative:

52. I was given time during which I was able to study.

This sentence is closely parallel to the finite relative in (51) - that I was given to study - with (the) time as its antecedent. The NP is definite, since the relative uniquely characterizes the time period considered, while it is not in (52), where the time period is just mentioned.

It could be argued that relativization occurs twice in (51). Schematically (the arrows now representing movement/relativization):

51. I enjoyed the time that I was given to study

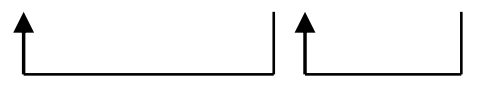

In point of fact, a similar construction was already used as an example:

20. [...] and also thank her for the much appreciated cherry cake she gave me to bring up -_ here.

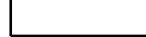

It is even possible for a $w h$ - relative pronoun to come up before to, as in (55):

53. Pressure is exerted on the player in possession of the ball by challenging him or moving towards him, cutting down on the time and space he has available in which to play. $(<w 2 d-015055>)$

This fact suggests that such to-infinitives should be seen as relative clauses.

Double relativization is an unusual phenomenon likely to be confused with longdistance extraction, through which an antecedent and a relative clause can become separated with bridge verbs ${ }^{12}$ like say, think, believe...

54. I am looking forward to the free time he said he would give us

54a. * I am looking forward to the free time I would enjoy he must give us

54b. * I am looking forward to the free time he must give us I would enjoy

Enjoy and give are not verbs like say: they do not allow long-distance extraction. It is remarkable that give, in (51) and (20), or have X available, in (53), appear to behave like say in (54). Yet these do not work like bridge verbs, though they allow double relativization with WPC infinitives.

How to account for double relativization? The solution is to consider WPC infinitives as primarily adverbial, and so not subject to restrictions prevailing for relative clauses - even though a continuative reading is entailed in the right environment. Syntactic ambiguity arises because a relative reading is superimposed on the adverbial one - to such an extent that a wh- 
relative pronoun can appear, as in (52). This provides the key to the puzzle we started with: unless a continuative reading is contextually blocked, WPCs can be parsed both as adjuncts and relative infinitives, the distinction being then neutralized.

\section{Conclusion}

My conception of "purposive" clauses that are not rationale clauses (i.e. WPCs) departs from that of preceding authors in several important respects. First, the category is much larger than formerly thought. This is because insufficient attention had been paid to the presence of gaps that are not conspicuous. The syntactic functions filled by gaps are also wider-ranging than previously assumed, and it is possible to have no gaps in WPCs. Second, an overwhelming majority of these infinitives can also be parsed as relative clauses, giving rise to the syntactic puzzle with which I started this article.

WPC infinitives are adjuncts primarily. Except when found in now familiar syntactic contexts, they can just as well be parsed as continuative clauses, owing to the weak purposive meaning derived from the initial WPC interpretation that immediately comes to mind when encountering them. Syntactic ambiguity arises from the superimposition of a continuative reading on an adverbial one. Assuming that continuative readings are derived post hoc in this manner elegantly explains that WPC infinitives can undergo "double relativization".

I would like to conclude with another argument in support of my unusual procedural, almost psycholinguistic, account of ambiguity for WPC infinitives. In ICE-GB, there are two interesting occurrences of WPC infinitives that should be reinterpreted as noun complement clauses rather than relative clauses:

You can ask specific questions on occasions... and now's the opportunity we've allocated to deal with that. $(<\mathrm{s} 1 \mathrm{~b}-015023>)$

While we were in Strasbourg recently, you mentioned to me the invitation you had received to speak at one of the series of Criminal justice Conferences being arranged in England. $(<w 1 b-027003>)$

Of course, an opportunity thanks to which you can deal with that and an invitation thanks to which I'll be able to speak... would have been acceptable paraphrases. However, the head nouns opportunity and invitation are not readily understood as coreferential with instrument gaps. The infinitive is better seen as a noun complement clause (content clause) rather than a relative. This militates strongly for the view that WPC infinitives are prone to reinterpretation, either as noun complement clauses or (mainly) continuative clauses, which leads to ambiguity and neutralization. 


\section{ENDNOTES}

*. I wish to thank Christian Mair and Wim van der Wurff for their helpful suggestions on an earlier version of this paper, as well as the two anonymous reviewers for their careful proofreading and insightful comments.

1. Troubetzkoy (1936) introduced neutralization as a phonological notion. In a syntactic context it corresponds to Bolinger's (1961) concept of generality: whatever interpretation is chosen, communication remains unimpaired.

2. Huddleston and Pullum (2002: 1067) make a distinction between wh infinitivals and non-wh infinitivals - as in She is the ideal person in whom to confide as opposed to She is the ideal person to confide in. Huddleston was the first to regard the latter as relative clauses without an apparent relative pronoun (Huddleston et al. 1968; see also Poutsma [1926: 786, 1929: 826] for a suggestion to that effect). Ambiguity arises for non-wh-infinitivals only, as $w h$ - pronouns rule out an adverbial purpose interpretation.

3. Cuyckens and de Smet (2007: 84) adduce a for ... to infinitive occurrence from FLOB to illustrate the potential ambiguity between a relative and an adverbial interpretation: "The measures announced by the Home Secretary following his review of peacetime emergency arrangements (see paragraph 14.1 above) included a wider remit for the College to address questions of peacetime emergency [their emphasis]."

4. The well-known distinction between restrictive and non-restrictive relative clauses will suffice for the present purpose, despite the pervading theoretical debate over its adequacy (see e.g., Huddleston and Pullum's 2002 new handling of the dichotomy).

5. As with the instrument function, a stranded preposition sometimes appears.

6. Yet simple negation does not prevent acceptability: the thug generally seems not to select elderly women to attack and rob is felicitous. This is perhaps best accounted for by assuming that with not, the negation has scope over to select elderly women and the WPC.

7. Although what has traditionally been referred to as control is now regarded by some syntacticians as pertaining to raising (see e.g., Broeckx and Hornstein 2006), this has no bearing on the argument developed here.

8. The animate entity benefiting from the availability predicated or entailed does not have to be explicitly referred to in the matrix clause, but may be left implicit, as in (25): ...the truth is always there to see (for anyone who takes enough time to look for it).

9. Huddleston (1971) and Quirk et al. (1985: 1270) remarked that IRCs could be appositive, which is also pointed out in the three doctoral dissertations on relative infinitives (Geisler 1995; Akiyama 2002; Simonin 2007). Yet such non-restrictive IRCs (e.g. This scholar, to be found daily in the British Museum, has devoted his life to the history of science) are singular enough not to be confused with WPCs (see e.g., Simonin 2007: 430$432, \S 8.1 .3)$.

10. Thompson $(1985: 56,82)$ makes the point for "purpose clauses" in general - and so for rationale clauses too; (43) is from van der Wurff (p.c.), and (44) from Kirkpatrick (1982: 101).

11. The following examples are from Jones (1991: 49).

12. The first account of this phenomenon is Chomsky 1964 [1962], according to Radford (1981: 220). 


\section{BIBLIOGRAPHY}

Akiyama, Takanobu. 2002. The infinitival relative clause in English: An analysis based on the British National Corpus. Lancaster: University of Lancaster doctoral dissertation.

Bach, Emmon. 1982. Purpose clause and control. In Pauline Jacobson \& Geoffrey K. Pullum (eds). The nature of syntactic representation, 35-57. Dordrecht: D. Reidel Publishing Company.

Bolinger, Dwight. L. 1961. Generality, gradience, and the all-or-none. The Hague: Mouton.

Broeckx, Cedric \& Hornstein, Norbert. 2006. The virtues of control as movement. Syntax 9, 118-130.

Chomsky, Noam. 1964 [1962]. The logical basis of linguistic theory. In Horace G. Lunt (ed.). The proceedings of the ninth international congress of linguists, paper presented at the Ninth International Congress of Linguists, Cambridge, MA, 27-31 August 1962, 914-978. The Hague: Mouton.

Cristofaro, Sonia. 2005. Purpose clauses. In Martin Haspelmath, Matthew S. Dryer, David Gil \& Bernard Comrie (eds). World atlas of world languages, 506-509. Oxford: Oxford University Press.

Culicover, Peter. W. \& Jackendoff, Ray. 2005. Simpler syntax. Oxford: Oxford University Press.

Cuykens, Hubert. \& de Smet, Hendrik. 2007. For ... to- infinitives from Early to Late Modern English. In Javier Pérez-Guerra, Dolores Gonzalez-Álvarez, Jorge L. Bueno-Alonso \& Esperanza Rama-Martínez (eds). Of varying language and opposing creed: New insights into late modern English, 77-103. Bern: Peter Lang.

Delesse, Catherine. 2001. Quelques réflexions sur les relatives infinitives. In Fabienne Toupin (ed.). Mélanges en l'honneur de Gérard Deléchelle (Groupe de Recherche AngloAméricaine de Tours). 41-50. Tours: Publications de 1'Université François Rabelais.

Doherty, Cathal. 2000. Clauses without "that": the case for bare sentential complementation in English. New York: Garland.

Faraci, Robert. A. 1974. Aspects of the grammar of infinitives and for-phrases. Cambridge, MA: MIT doctoral dissertation.

Geisler, Christer. 1995. Relative infinitives in English (Acta Universitatis Upsaliensis: Studia Anglistica Upsaliensia 91). Stockholm: Almquist \& Wiksell.

Givòn, Talmy. 1990. Syntax: A functional-typological approach, volume 2. Amsterdam: John Benjamins.

Green, Georgia. M. 1991. Purpose infinitives and their relatives (Cognitive Science Technical Report CS-91-04), 1-28. Urbana-Champaign: University of Illinois.

Green, Georgia. M. 1992. Purpose infinitives and their relatives. In Diane Brentari, Gary N. Larson \& Lynne A. Macleod (eds). The joy of grammar, 95-130. Amsterdam: John Benjamins.

Hannay, Michael \& Mackenzie, J. Lachlan. 1996. Effective writing in English: A resource guide, 114 -116. Groningen: Martinus Nijhoff.

Huddleston, Rodney D., Hudson, Richard A., Winter, Eugene O., \& Henrici, Alec. 1968. Sentence and clause in scientific English (OSTI report 5030). London: University College London.

Huddleston, Rodney D. \& Pullum, Geoffrey K. 2002 (eds). The Cambridge grammar of the English language. Cambridge: Cambridge University Press.

Jackendoff, Ray \& Culicover, Peter W. 2003. The semantic basis of control in English. Language 79, 517-556.

Jespersen, Otto. 1927. A modern English grammar on historical principles, part III, syntax: volume 2. Heidelberg: Winter. 
Jespersen, Otto. 1940. A modern English grammar on historical principles, part V, syntax: volume 4. Heidelberg: Winter.

Jones, Charles. 1985. Agent, patient, and control into purpose clauses. Chicago Linguistics Society 21, 105-119.

Jones, Charles. 1991. Purpose clauses: Syntax, thematics, and semantics of English clause purpose constructions (Studies in Linguistics and Philosophy 47). Dordrecht: Kluwer Academic Publishers.

Kirkpatrick, Charles. 1982. The transitive purpose clause in English. Texas Linguistic Forum 19, 99-123.

Kitagawa, Chisato. 1974. Purpose expressions in English. Lingua 31, 31-46.

Kitagawa, Chisato. 1976. Purpose expressions and characterization of volitive NPs. Linguistics 82, 53-65.

Landau, Idan. 2000. Elements of control: Structure and meaning in infinitival constructions (Studies in Natural Language and Linguistic Theory 19). Dordrecht: Kluwer Academic Publishers.

Mair, Christian. 1990. Infinitival complement clauses in English. Cambridge: Cambridge University Press.

Mair, Christian. 1991. Quantitative or qualitative corpus analysis? In Stig Johansson \& AnnaBrita Stenström (eds). English computer corpora: Selected papers and research guide, 6780. Berlin: Mouton de Gruyter.

Onions, Charles. T. 1971 [1904]. Modern English syntax, new edition of An advanced English syntax. London: Routledge \& Kegan Paul.

Poutsma, Hendrik. 1926. A grammar of late modern English, part II, section II. Groningen: P. Noordhoff.

Poutsma, Hendrik. 1929 [1914]. A grammar of Late Modern English. part I, second half: the composite sentence, $2^{\text {nd }}$ edition. Groningen: P. Noordhoff.

Quirk, Randolph. 1977. A tough object to trace. Journal of Linguistics 13, 99-102.

Quirk, Randolph, Greenbaum, Sydney, Leech, Geoffrey \& Svartvik, Jan 1985. A comprehensive grammar of the English language. London: Longman.

Radford, Andrew. 1981. Transformational syntax: A student's guide to Chomsky's extended standard theory. Cambridge: Cambridge University Press.

Rydén, Mats. 1966. Relative constructions in early $16^{\text {th }} \mathrm{C}$ English (Acta Universitatis Upsaliensis, Studia Anglistica Upsaliensia 3). Stockholm: Almquist \& Wiksell.

Simonin, Olivier. 2007. Relatives infinitives et constructions apparentées. Paris: Université de Paris-Sorbonne (Paris 4) doctoral dissertation.

Thompson, Sandra A. 1985. Grammar and written discourse: Initial vs. final purpose clauses in English. Text 5, 55-84.

Troubetkoy, Nikolaj. 1936. La neutralisation des oppositions phonologiques. Travaux du cercle linguistique de Prague 6, 46-56.

Whelpton, Matthew. J. 1995. The syntax and semantics of infinitives of result in English. Oxford: University of Oxford doctoral dissertation.

Whelpton, Matthew. J. 2001. Elucidation of a telic infinitive. Journal of Linguistics 37, 313337.

Whelpton, Matthew. J. 2006. Now what did you do that for? - Some comments on purpose infinitives and event teleology. In Haraldur Bernharðsson et al. (eds), Hugvísindaping 2005: Erindi af ráðstefnu Hugvísindadeildar og Guðfræðideildar Háskóla Íslands 18. nóvember 2005, p. 209-222. Reykjavik, Iceland: Hugvísindastofnun Háskóla Íslands.

Wurff, Wim van der 2002. The word withal: Some remarks on its historical development. In Jacek Fisiak (ed.) Studies in English historical linguistics and philology: A festschrift for Akio Oizumi, 469-487. Bern: Peter Lang. 
Olivier Simonin is lecturer in English linguistics at the University of Perpignan. He defended his doctoral dissertation on Relative Infinitives in English and Related Constructions (written in French) in 2007. 